\title{
Cardiovascular Outcomes Post Percutaneous Coronary Intervention in Patients with Obstructive Sleep Apnea and Type 2 Diabetes Mellitus: A Systematic Review and Meta-Analysis
}

Hong Wang $\cdot$ Xinxin Li · Zhangui Tang $\cdot$ Guoping Gong

Received: May 29, 2020 / Published online: June 26, 2020

(C) The Author(s) 2020

\section{ABSTRACT}

Introduction: Type 2 diabetes mellitus (T2DM) is a major risk factor for the occurrence of cardiovascular diseases. Similar to T2DM, obstructive sleep apnea (OSA) is also known to be a risk factor for cardiovascular diseases. In this analysis, we aimed to systematically compare the post-interventional cardiovascular outcomes observed in patients with T2DM with versus without OSA.

Methods: Electronic databases were searched for relevant publications comparing the cardiovascular outcomes following percutaneous coronary intervention (PCI) in patients with T2DM with OSA. Cardiovascular outcomes were considered as the relevant endpoints. The RevMan software 5.3 was used to carry out the statistical analysis. Odds ratios (OR) with 95\% confidence intervals (CI) were used to represent the results following data assessment.

Digital Features To view digital features for this article go to https://doi.org/10.6084/m9.figshare.12505346.

H. Wang $(\bowtie) \cdot$ X. Li · G. Gong

Department of Cardiology, The People's Hospital of Guangxi Zhuang Autonomous Region, Nanning,

Guangxi, China

e-mail: iriswh2014@163.com

\section{Z. Tang}

Department of Cardiovascular Disease, Xiangya

Hospital, Central South University, Changsha,

Hunan, People's Republic of China
Results: A total of 1168 participants with T2DM were included in this analysis, of whom 614 had co-existing OSA. The time period of patients' enrollment varied from year 2002 to 2017. Our current analysis showed that major adverse cardiac events (MACEs) (OR 2.28, 95\% CI 1.24-4.18; $P=0.008$ ) and all-cause mortality (OR 1.95, 95\% CI 1.08-3.54; $P=0.03$ ) were significantly higher in the OSA subgroup. However, major adverse cerebrovascular and cardiovascular (MACCEs) (OR 1.38, 95\% CI 0.97-1.98; $P=0.07$ ) and cardiac death (OR 1.79, 95\% CI $0.77-4.16$; $P=0.18$ ) were not significantly different post PCI. In addition, hospitalization for heart failure (OR 1.99, 95\% CI 0.43-9.25; $P=0.38$ ), re-infarction (OR 1.52, 95\% CI 0.85-2.70; $P=0.16$ ), stroke (OR 1.81, 95\% CI $0.81-4.08 ; \quad P=0.15)$, target vessel revascularization (TVR) (OR 1.54, 95\% CI $0.98-2.42 ; P=0.06$ ), and target lesion revascularization (TLR) (OR 1.32, 95\% CI 0.80-2.18; $P=0.28$ ) were also not significantly different post PCI in the patients with T2DM with versus without OSA.

Conclusion: OSA was associated with a significant increase in all-cause mortality and MACEs post PCI in these patients with T2DM. Therefore, special care and continuous follow-up might be required for patients with T2DM with associated OSA after PCI. However, as a result of the limited number of participants, further larger studies would be required to confirm these hypotheses. 
Keywords: Major adverse cardiac events; Obstructive sleep apnea; Percutaneous coronary intervention; Type 2 diabetes mellitus

\section{Key Summary Points}

Why carry out this study?

Similar to diabetes mellitus, obstructive sleep apnea (OSA) is also known to be a risk factor for cardiovascular diseases.

However, no study has yet systematically assessed the cardiovascular outcomes in patients with co-existing diabetes mellitus and OSA following coronary angioplasty.

What was learned from the study?

OSA was associated with a significant increase in all-cause mortality and major adverse cardiac events post coronary intervention in these patients with diabetes mellitus.

Therefore, special care and continuous follow-up might be required for patients with diabetes mellitus with associated OSA following percutaneous coronary intervention.

\section{INTRODUCTION}

It is well known that type 2 diabetes mellitus (T2DM) is a major risk factor for the occurrence of cardiovascular diseases [1]. Similar to T2DM, obstructive sleep apnea (OSA) [2], characterized by recurrent partial or complete upper airway obstruction causing hypoxia and arousal from sleep, is also known to be a risk factor for cardiovascular diseases [3]. Several studies have already shown T2DM to be associated with worse cardiovascular outcomes following percutaneous coronary intervention (PCI) [4]. Recent studies have also shown that in those patients with acute coronary syndrome (ACS), OSA is associated with a higher risk of shortand long-term cardiovascular events compared to those patients without OSA [5]. However, no study has yet systematically assessed the cardiovascular outcomes in patients with co-existing T2DM and OSA following coronary angioplasty. In this analysis, we aimed to systematically compare the post-interventional cardiovascular outcomes observed in patients with T2DM with versus without OSA.

\section{METHODS}

\section{Data Sources}

The following search databases were explored for relevant publications:

MEDLINE
Cochrane Central
https://www.ClinicalTrials.gov
EMBASE
Web of Science
Google Scholar

\section{Searched Terms and Search Strategies}

The aforementioned databases were searched for relevant publications comparing the cardiovascular outcomes in patients with T2DM with versus without OSA following PCI by using the following search terms:

- Obstructive sleep apnea, diabetes mellitus, percutaneous coronary intervention

- Obstructive sleep apnea and percutaneous coronary intervention

- Obstructive sleep apnea, type 2 diabetes mellitus, percutaneous coronary intervention

- Obstructive sleep apnea, diabetes mellitus, coronary angioplasty

- Obstructive sleep apnea, diabetes mellitus, coronary revascularization

- Obstructive sleep apnea, coronary angioplasty

- Obstructive sleep apnea, diabetes mellitus, PCI

Only studies published in English language were considered relevant to this research. 
Table 1 Outcomes reported in these patients with type 2 diabetes mellitus

\begin{tabular}{|c|c|c|c|}
\hline Studies & Outcomes reported & $\begin{array}{l}\text { Approximate mean } \\
\text { follow-up time period }\end{array}$ & $\begin{array}{l}\text { Treatment } \\
\text { strategy }\end{array}$ \\
\hline Fan $[8]$ & $\begin{array}{l}\text { MACCE, cardiovascular death, MI, stroke, hospitalization for } \\
\text { unstable angina, hospitalization for heart failure, all-cause } \\
\text { mortality, TVR, TLR }\end{array}$ & 1 year & $\begin{array}{l}\text { PCI or } \\
\text { CABG }\end{array}$ \\
\hline Lee $[9]$ & $\begin{array}{l}\text { Death, re-infarction, stroke, TVR, admission due to heart failure, } \\
\text { major adverse events }\end{array}$ & 18 months & PCI \\
\hline Lee $[10]$ & $\begin{array}{l}\text { MI, stroke, revascularization, stent thrombosis, MACCE, } \\
\text { cardiovascular death, all-cause mortality }\end{array}$ & 1.9 years & PCI \\
\hline Loo $[11]$ & $\begin{array}{l}\text { MI, revascularization, stroke, hospitalization for heart failure, } \\
\text { cardiac death, MACCE }\end{array}$ & 24 months & PCI \\
\hline Meng [12] & MACEs, cardiac death, heart failure, TVR, stroke & 1 year & PCI \\
\hline $\begin{array}{l}\text { Nakashima } \\
\text { [13] }\end{array}$ & TVR, re-infarction, MACEs & 4 years & PCI \\
\hline Wu [14] & Revascularization, TLR, TVR, MI, stroke, death, MACE, MACCE & 1 and 5 years & PCI \\
\hline $\begin{array}{c}\text { Yumino } \\
{[15]}\end{array}$ & TVR, cardiac death, MACEs & 8 months & PCI \\
\hline
\end{tabular}

MACCEs major adverse cardiovascular and cerebrovascular events, MACEs major adverse cardiac events, $M I$ myocardial infarction, TVR target vessel revascularization, TLR target lesion revascularization, $P C I$ percutaneous coronary intervention, $C A B G$ coronary artery bypass grafting

\section{Inclusion and Exclusion Criteria}

Criteria for inclusion were:

Patients with T2DM with OSA who have undergone PCI.

Post-PCI cardiovascular outcomes were reported.

English publications.

\section{Criteria for exclusion:}

Patients with T2DM without OSA.

Post-interventional cardiovascular outcomes were not reported.

Repeated studies.

Non-English publications.

Literature reviews, meta-analyses and systematic reviews as well as case studies.

\section{Outcomes}

The outcomes assessed in this analysis were:

Major adverse cerebrovascular and cardiac events (MACCEs), defined as the total number of deaths, re-infarction, revascularization, and stroke

Major adverse cardiac events (MACEs), defined as the total number of deaths, reinfarction, and revascularization

Cardiac death

All-cause mortality

Re-infarction

Stroke

Target vessel revascularization (TVR)

Target lesion revascularization (TLR)

Hospitalization for heart failure.

All patients were revascularized by PCI. The outcomes reported in the original studies are listed in Table 1. 
The mean follow-up time period ranged between 1 and 5 years.

\section{Data Extraction and Quality Assessment}

Data were extracted by four independent authors. First of all the first authors' names, the publication year, the total number of participants with T2DM, the total number of participants with T2DM with versus without OSA, the baseline characteristics including the mean age of the participants, the percentage of male patients, the percentage of participants with T2DM who were current smokers, who had hypertension, and those who had dyslipidemia were all carefully extracted. In addition, the type of study, the type of revascularization procedures, the time period of patients' enrollment, the cardiovascular outcomes reported in the original studies, and the corresponding follow-up time period were all carefully extracted.

If any of the authors disagreed about the inclusion of certain data or had any difficulty in the data extraction process, the issues were carefully discussed among all the authors, and then a final decision was made by the corresponding author.

The methodological quality of the studies was assessed by the Newcastle Ottawa Scale (NOS) [6]. Grades were allotted to the studies to denote low (A), moderate (B), or high risk (C) of bias.

\section{Statistical Analysis}

The RevMan software 5.3 was used to carry out the statistical analysis. Odds ratios (OR) with 95\% confidence intervals (CI) were used to represent the results following data assessment. There were two ways to assess heterogeneity: (1) using the $Q$ statistic test whereby a $P$ value less than or equal to 0.05 was considered statistically significant; (2) the $I^{2}$ test whereby heterogeneity was increased with an increasing $I^{2}$ value. An $I^{2}$ value with a low percentage denoted low heterogeneity whereas an $I^{2}$ value with a high percentage denoted increased heterogeneity.
A fixed statistical effect was used during data analysis if the heterogeneity was low; however, a random statistical effect model was used in case of high heterogeneity.

Sensitivity analysis was also carried out to prove that the main results were not influenced by any of the studies. In addition, a funnel plot was generated to visually assess publication bias.

\section{Compliance with Ethical Guidelines}

This article is based on previously conducted studies and does not contain any studies with human participants or animals performed by any of the authors.

\section{RESULTS}

\section{Search Outcomes}

The Preferred Reporting Items for Systematic Reviews and Meta-Analysis (PRISMA) guideline was followed [7]. A thorough search through the electronic databases resulted in a total of 1080 publications. After an assessment of the titles and abstracts by the authors, 988 publications were eliminated and the remaining 92 full-text publications were assessed for eligibility.

Full-text articles were eliminated on the basis of the following criteria:

Involved participants did not undergo PCI $(n=7)$.

Post-interventional outcomes were not reported $(n=3)$.

Non-English publications $(n=4)$.

Case studies $(n=6)$.

Literature review $(n=1)$.

Systematic reviews and meta-analyses $(n=3)$. Repeated studies $(n=60)$.

Finally only eight studies [8-15] were included in this analysis as shown in Fig. 1. 


\section{Main and Baseline Features}

Table 2 shows the main characteristics of the studies included in this analysis. The time period of patients' enrollment varied from year 2002 to 2017. A total of 1168 participants with T2DM were included in this analysis, of whom 614 had co-existing OSA.

On the basis of the assessment by the NOS, a grade $\mathrm{B}$ was allotted to the studies indicating a moderate risk of bias as shown in Table 2 .

The baseline features of the studies are listed in Table 3. According to the baseline features listed, the mean age of the participants ranged between 50.9 and 71.0 years. The majority of these patients with T2DM were male participants with an average percentage ranging from
$66.7 \%$ to $98.4 \%$. The mean percentages of participants with hypertension (49.2\% to $79.2 \%)$, dyslipidemia $(25.7 \%$ to $88.6 \%)$, and current smoker $(16.7 \%$ to $63.6 \%)$ are also given in Table 3.

\section{Results of this Analysis}

All patients with T2DM with or without OSA who underwent PCI were included. Our current analysis showed that MACEs (OR 2.28, 95\% CI 1.24-4.18; $P=0.008$ ) and all-cause mortality (OR 1.95, 95\% CI 1.08-3.54; $P=0.03$ ) were significantly higher in the OSA subgroup as shown in Fig. 2. However, MACCEs (OR 1.38, 95\% CI 0.97-1.98; $P=0.07$ ) and cardiac death (OR 1.79, 95\% CI 0.77-4.16; $P=0.18$ ) were not

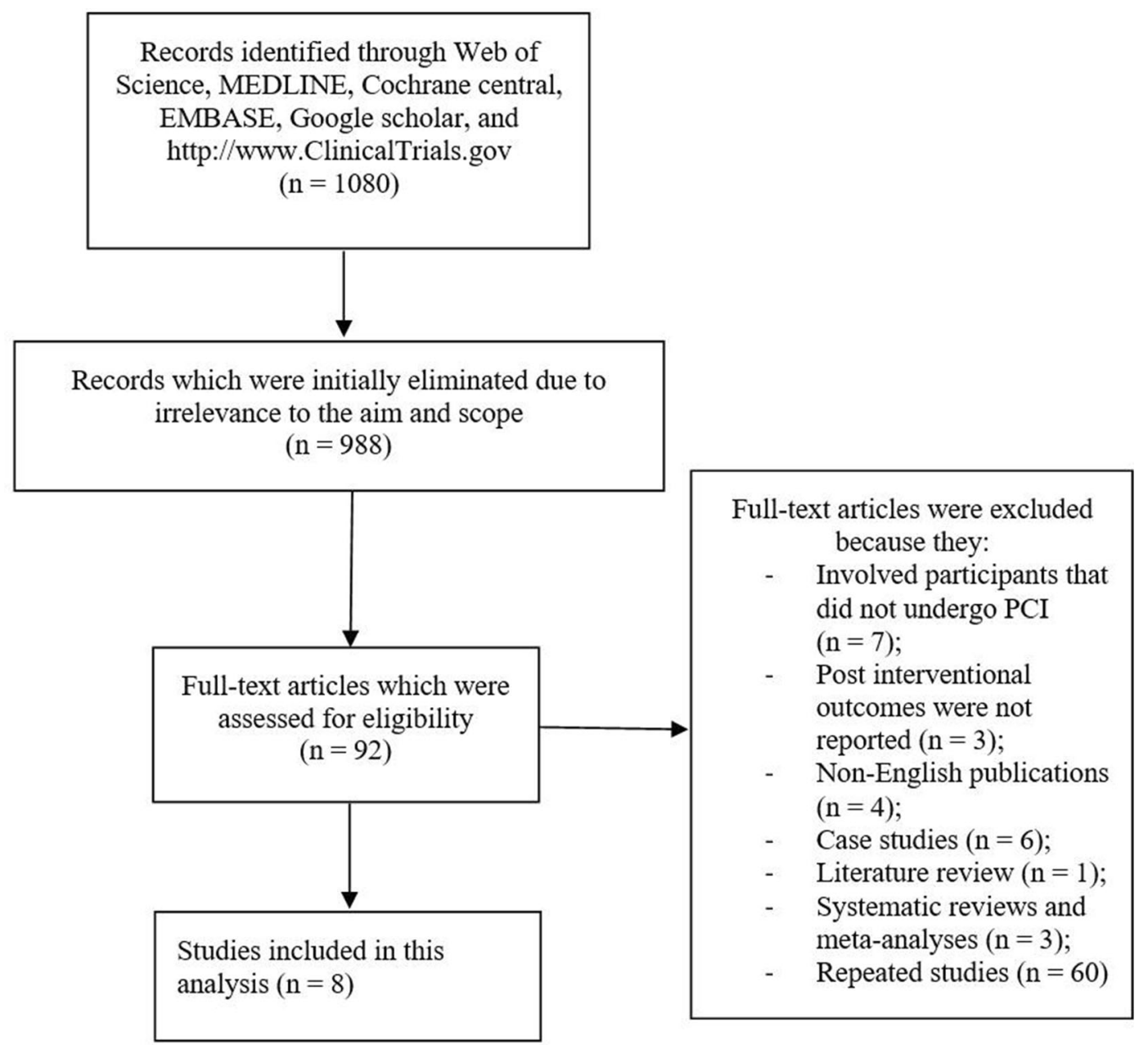

Fig. 1 Flow diagram representing the selection of studies to be included in this analysis 
Table 2 Main features of the studies

\begin{tabular}{|c|c|c|c|c|c|}
\hline Studies & $\begin{array}{l}\text { Type of } \\
\text { study }\end{array}$ & $\begin{array}{l}\text { Year of } \\
\text { participants' } \\
\text { enrollment }\end{array}$ & $\begin{array}{l}\text { No. of patients with } \\
\text { T2DM with OSA }(n)\end{array}$ & $\begin{array}{l}\text { No. of patients with } \\
\text { T2DM without OSA }(n)\end{array}$ & $\begin{array}{l}\text { NOS } \\
\text { grade }\end{array}$ \\
\hline Fan $[8]$ & Prospective & $2015-2017$ & 121 & 127 & B \\
\hline Lee [9] & Prospective & 2007-2008 & 21 & 21 & B \\
\hline Lee $[10]$ & Prospective & 2011-2014 & 271 & 284 & B \\
\hline Loo [11] & Prospective & 2011-2012 & 9 & 8 & B \\
\hline Meng [12] & OS & 2008 & 19 & 11 & B \\
\hline Nakashima [13] & OS & 2003-2009 & 45 & 51 & B \\
\hline Wu [14] & Retrospective & $2002-2012$ & 100 & 33 & B \\
\hline Yumino [15] & OS & & 28 & 19 & B \\
\hline $\begin{array}{l}\text { Total no. of } \\
\text { participants with } \\
\text { T2DM }(n)\end{array}$ & & & 614 & 554 & \\
\hline
\end{tabular}

$O S$ observational study, T2DM type 2 diabetes mellitus, $O S A$ obstructive sleep apnea, NOS Newcastle Ottawa Scale

Table 3 Baseline features of the participants with T2DM with versus without OSA

\begin{tabular}{lllllll}
\hline Studies & $\begin{array}{l}\text { Age (years) } \\
\text { OSA/NOSA }\end{array}$ & $\begin{array}{l}\text { Male (\%) } \\
\text { OSA/NOSA }\end{array}$ & $\begin{array}{l}\text { HBP (\%) } \\
\text { OSA/NOSA }\end{array}$ & $\begin{array}{l}\text { DYS (\%) } \\
\text { OSA/NOSA }\end{array}$ & $\begin{array}{l}\text { CS (\%) } \\
\text { OSA/NOSA }\end{array}$ & $\begin{array}{l}\text { DM (\%) } \\
\text { OSA/NOSA }\end{array}$ \\
\hline Fan [8] & $57.7 / 57.2$ & $84.9 / 80.3$ & $68.2 / 63.6$ & $26.6 / 25.7$ & $50.1 / 50.9$ & $100 / 100$ \\
Lee [9] & $55.2 / 50.9$ & $97.7 / 98.4$ & $56.8 / 49.2$ & $88.6 / 80.3$ & $54.6 / 60.7$ & $100 / 100$ \\
Lee [10] & $59.0 / 57.5$ & $88.1 / 82.9$ & $68.0 / 54.0$ & $60.1 / 58.7$ & $35.4 / 35.6$ & $100 / 100$ \\
Loo [11] & $56.7 / 52.8$ & $75.0 / 93.2$ & $66.7 / 38.6$ & $87.5 / 70.5$ & $16.7 / 63.6$ & $100 / 100$ \\
Meng [12] & $66.5 / 66.8$ & $70.7 / 66.7$ & $75.7 / 79.2$ & $68.9 / 66.7$ & $36.5 / 31.3$ & $100 / 100$ \\
Nakashima [13] & $71.0 / 65.0$ & $77.0 / 73.0$ & $63.0 / 56.0$ & $56.0 / 55.0$ & $32.0 / 45.0$ & $100 / 100$ \\
Wu [14] & $55.0 / 55.0$ & $84.2 / 83.2$ & $73.8 / 70.5$ & $44.6 / 40.0$ & $24.6 / 23.2$ & $100 / 100$ \\
Yumino [15] & $66.0 / 65.0$ & $84.0 / 68.0$ & $78.0 / 79.0$ & $84.0 / 53.0$ & $63.0 / 58.0$ & $100 / 100$ \\
\hline
\end{tabular}

HBP high blood pressure, DYS dyslipidemia, CS current smoker, DM diabetes mellitus, OSA obstructive sleep apnea, NOSA non-obstructive sleep apnea

significantly different post PCI between these two subgroups of patients with T2DM with versus without OSA as shown in Fig. 2.

In addition, hospitalization for heart failure (OR 1.99, 95\% CI 0.43-9.25; $P=0.38$ ), re-infarction (OR 1.52, 95\% CI 0.85-2.70; $P=0.16$ ), stroke (OR 1.81, 95\% CI 0.81-4.08; $P=0.15$ ),
TVR (OR $1.54,95 \%$ CI $0.98-2.42 ; P=0.06$ ) and TLR (OR 1.32, 95\% CI 0.80-2.18; $P=0.28$ ) were also not significantly different post PCI as shown in Fig. 3.

Sensitivity analysis was carried out by an exclusion method whereby each study was excluded one by one and a new analysis was 


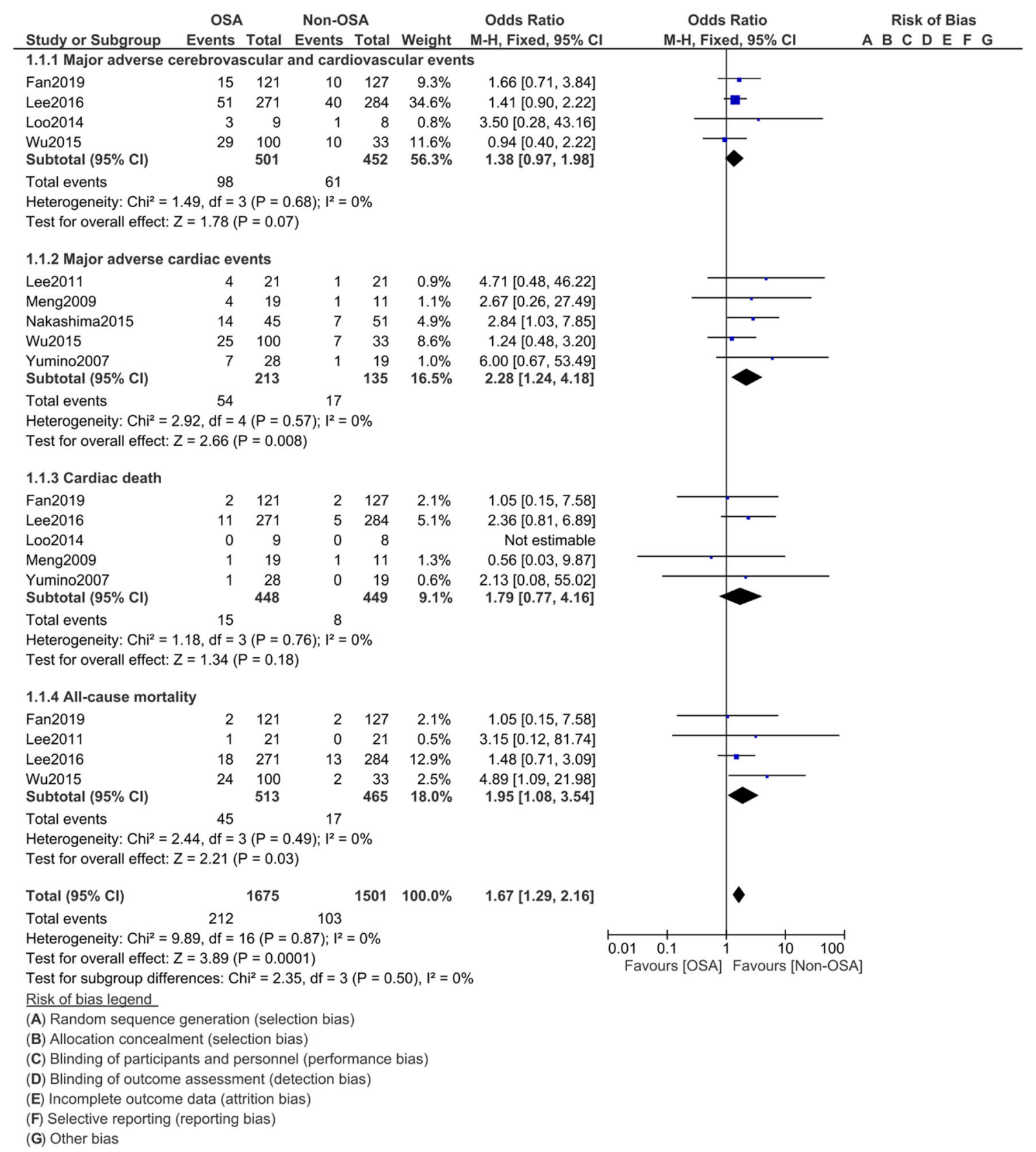

Fig. 2 Comparing the post-percutaneous coronary interventional outcomes in patients with T2DM with versus without obstructive sleep apnea (part I)

carried out each time and the new results were compared for any significant change compared to the main result of this analysis. However, consistent results were obtained throughout.

The funnel plot (Fig. 4) showed that there was no evidence of publication bias among the studies that were included to assess these cardiovascular outcomes post PCI in these patients with T2DM with versus without OSA.

A summary of the results is shown in Table 4. 


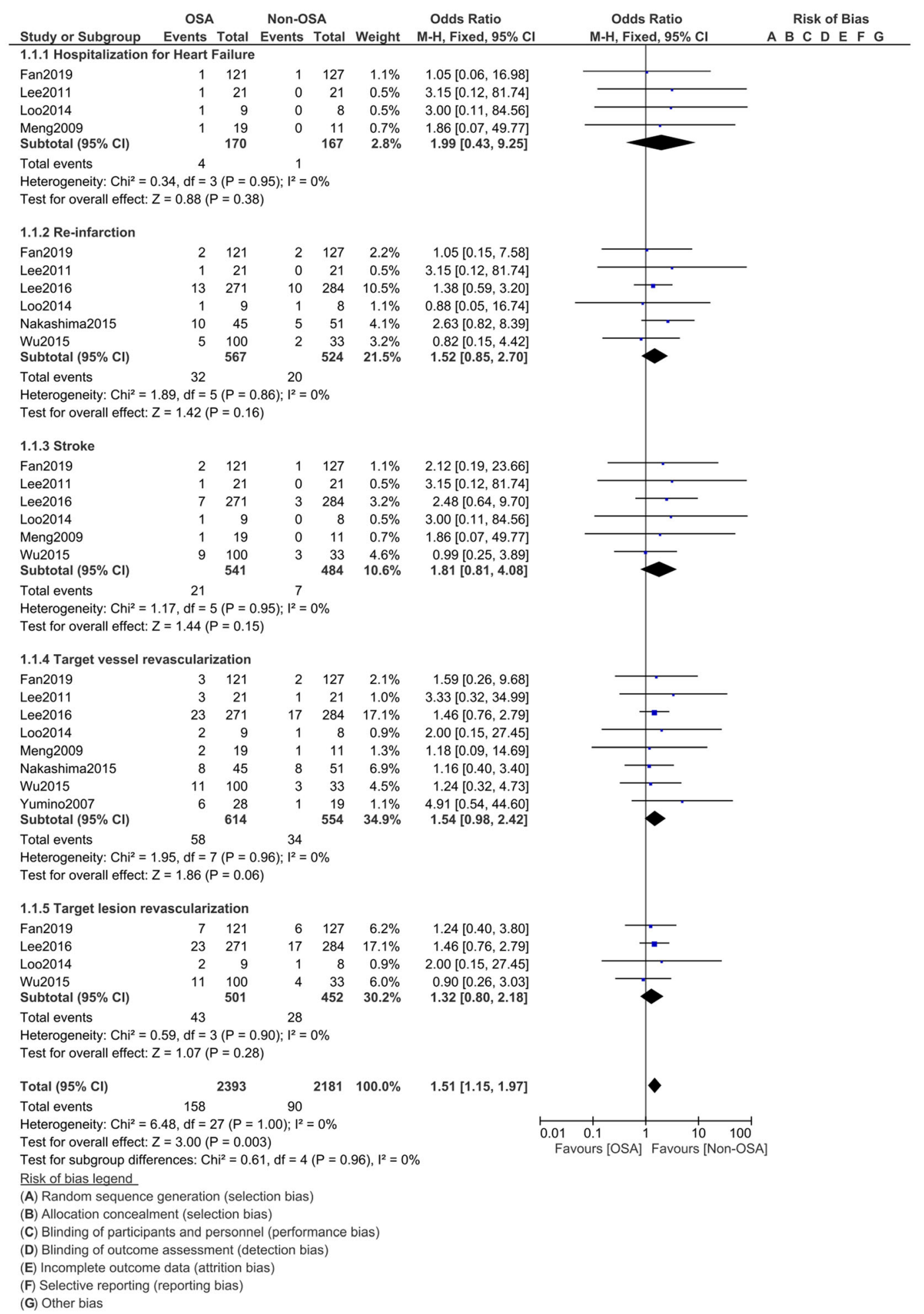

Fig. 3 Comparing the post-percutaneous coronary interventional outcomes in patients with T2DM with versus without obstructive sleep apnea (part II) 


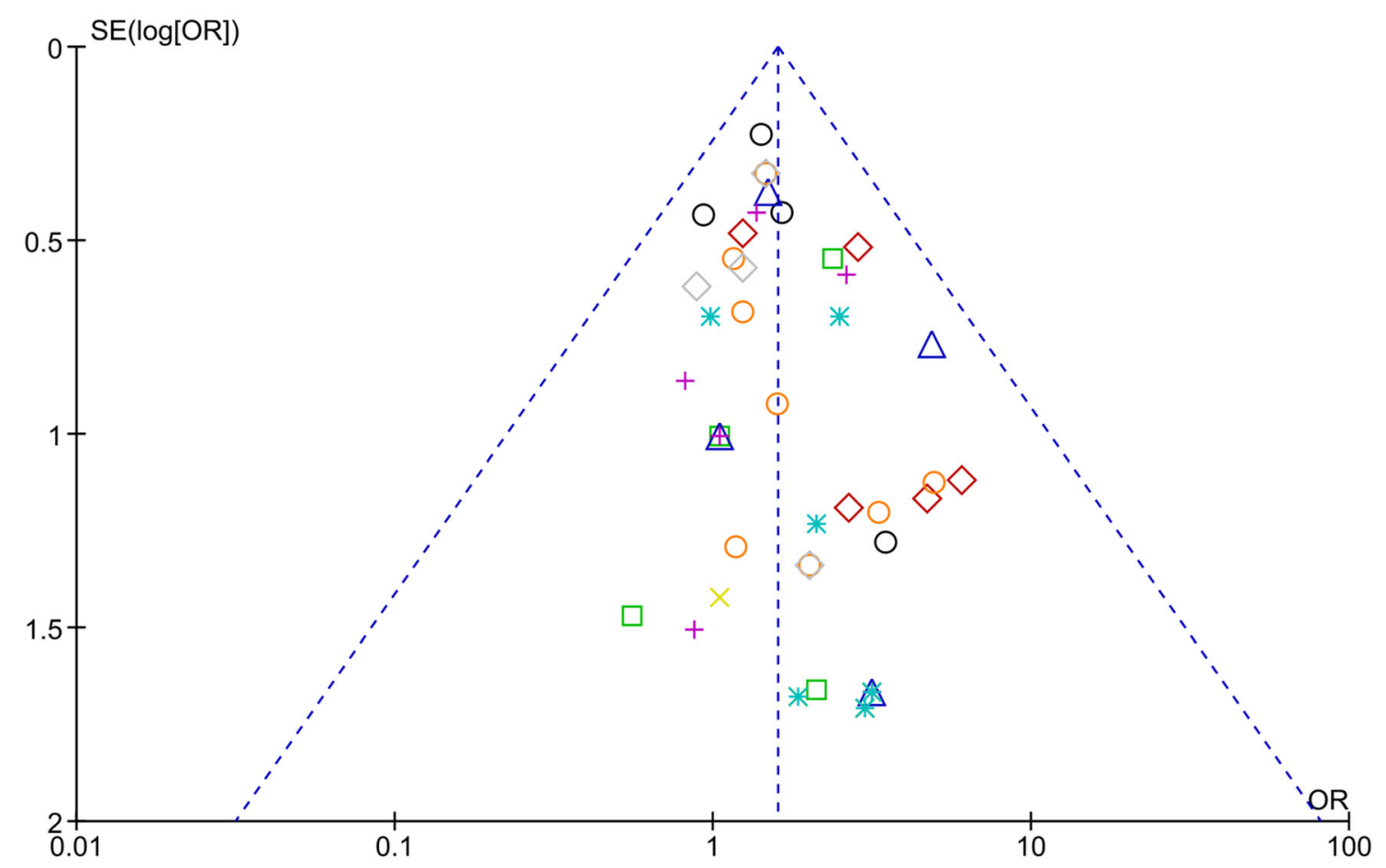

$$
\begin{aligned}
& \text { Subgroups } \\
& \text { Major adverse cerebrovascular and cardiovascular events } \\
& \square \text { Major adverse cardiac events } \\
& \triangle \text { Cardiac death } \\
& \text { All-cause mortality } \\
& + \text { Hespitalization for Heart Failure } \\
& * \text { Stroke } \\
& \text { Target vessel revascularization } \\
& \text { Target lesion revascularization }
\end{aligned}
$$

Fig. 4 Funnel plot visually demonstrating no publication bias

\section{DISCUSSION}

In a systematic review and meta-analysis which was published in 2012, the authors concluded that even though OSA appeared to be associated with stroke, the relationship between OSA and acute coronary syndrome or cardiovascular mortality would require further research [16]. This current analysis focused on the post-interventional cardiovascular outcomes observed in patients with T2DM with versus without OSA.

Our results from this analysis have shown that in patients with T2DM, OSA was associated with a significantly higher all-cause mortality and MACEs following coronary angioplasty. However, the results for re-infarction, repeated revascularization, cardiac death, MACCEs, stroke, and re-hospitalization for heart failure were not significant.

The fact that MACEs were significantly higher in patients with T2DM and co-existing OSA whereas MACCEs were not significantly different following PCI might be explained by the all-cause mortality being significantly higher, thereby contributing to significantly higher MACEs whereas stroke was not significantly different between these two groups, rendering MACCEs non-significant. 
Table 4 Results of this analysis

\begin{tabular}{|c|c|c|c|}
\hline Outcomes & $\begin{array}{l}\text { OR with } 95 \% \\
\text { CI }\end{array}$ & $P$ value & $\begin{array}{l}I^{2} \\
\text { value } \\
(\%)\end{array}$ \\
\hline $\begin{array}{l}\text { Major adverse } \\
\text { cardiovascular and } \\
\text { cerebrovascular } \\
\text { events (MACCEs) }\end{array}$ & $1.38[0.97-1.98]$ & 0.07 & 0 \\
\hline $\begin{array}{l}\text { Major adverse } \\
\text { cardiac events } \\
\text { (MACEs) }\end{array}$ & $2.28[1.24-4.18]$ & 0.008 & 0 \\
\hline Cardiac death & $1.79[0.77-4.16]$ & 0.18 & 0 \\
\hline All-cause mortality & $1.95[1.08-3.54]$ & 0.03 & 0 \\
\hline $\begin{array}{l}\text { Hospitalization for } \\
\text { heart failure }\end{array}$ & $1.99[0.43-9.25]$ & 0.38 & 0 \\
\hline Re-infarction & $1.52[0.85-2.70]$ & 0.16 & 0 \\
\hline Stroke & $1.81[0.81-4.08]$ & 0.15 & 0 \\
\hline $\begin{array}{l}\text { Target vessel } \\
\text { revascularization } \\
\text { (TVR) }\end{array}$ & $1.54[0.98-2.42]$ & 0.06 & 0 \\
\hline $\begin{array}{l}\text { Target lesion } \\
\text { revascularization } \\
\text { (TLR) }\end{array}$ & $1.32[0.80-2.18]$ & 0.28 & 0 \\
\hline
\end{tabular}

$O R$ odds ratios, $C I$ confidence intervals

OSA has been linked to cardiovascular events by several mechanisms [17]. Studies have shown repeated cycles of intermittent hypoxemia, sympathetic activation, and sleep disruption as a result of OSA could lead to several vascular abnormalities such as endothelial dysfunction, vascular inflammation, and high platelet reactions [18].

Similar to the results of this current study, another recently published meta-analysis based on the association of OSA with cardiovascular outcomes after PCI showed a significantly higher risk of MACEs and all-cause mortality associated with this intermittent hypoxemic disease [19]. The authors concluded that patients with OSA had a greater risk of subsequent cardiovascular outcomes after PCI. They also stated that whether prevention of OSA might improve cardiovascular outcomes should further be investigated. A recent meta-analysis of prospective studies additionally showed that OSA apparently increased the risk of cardiac death, repeated revascularization, and non-fatal myocardial infarction after PCI [20]. Nevertheless, the study dealt with the general population with coronary artery disease whereas our current paper was based on patients with T2DM with coronary artery disease.

In another study aimed at showing the clinical significance of OSA in patients with ACS in relation to diabetes status, OSA was associated with a higher risk of MACCEs at 1-year follow-up, following ACS in these patients with diabetes mellitus, but with different results in patients without diabetes mellitus [21]. The study also showed that longer hypoxia in these patients with diabetes mellitus and OSA could further increase the risk of MACCEs to $31 \%$. Similarly, among 168 consecutive patients who were admitted with unstable angina or non-ST elevation ACS, the authors suggested that OSA might represent an aggravating factor for such patients [22].

\section{Limitations}

This study has several limitations. Firstly, the total number of participants was small and this might have had an impact on the results and conclusion. Secondly, a few important cardiovascular outcomes including stent thrombosis were not assessed since they were not reported in the original studies, or were reported in only one study whereby a comparison was not possible. In addition, since the participants were on anticoagulants, bleeding outcomes would have also been interesting, but these outcomes were not reported in the original studies and therefore could not be analyzed in our paper. Another limitation could be the inclusion of data which were extracted from observational studies and could have contributed to the introduction of bias. 


\section{CONCLUSION}

OSA was associated with a significant increase in all-cause mortality and MACEs post PCI in these patients with T2DM. Therefore, special care and continuous follow-up might be required for patients with T2DM with associated OSA following PCI. As a result of the limited number of participants, further larger studies would be required to confirm these hypotheses.

\section{ACKNOWLEDGEMENTS}

Funding. No external funding or sponsorship was received for the publication of this article. This work was supported by Guangxi Medical and Health Appropriate Technology Development and Promotion Application Project (S2017077) and the Guangxi Nanning Qingxiu District Science and Technology Development Project (Grant No. 2014S06).

Authorship. All authors meet the International Committee of Medical Journal Editors (ICMJE) criteria for authorship for this article, take responsibility for the integrity of the work as a whole, and have given their approval for this version to be published.

Authorship Contributions. Hong Wang, Xinxin Li, Zhangui Tang, and Guoping Gong were responsible for the conception and design, acquisition of data, analysis and interpretation of data, drafting the initial manuscript and revising it critically for important intellectual content. Hong Wang, Xinxin Li, Zhangui Tang, and Guoping Gong approved the final manuscript as it is.

Disclosures. The authors Dr Hong Wang, Dr Xinxin Li, Dr Zhangui Tang, and Dr Guoping Gong declare that they have no competing interests.

Compliance with Ethics Guidelines. This meta-analysis is based on previously conducted studies and does not contain any studies with human participants or animals performed by any of the authors.

Data Availability. All data generated or analyzed during this study are included in this published article. References of the original papers involving the data source which have been used in this paper have been listed in the main text of this current manuscript. All data are publicly available in electronic databases.

Open Access. This article is licensed under a Creative Commons Attribution-NonCommercial 4.0 International License, which permits any non-commercial use, sharing, adaptation, distribution and reproduction in any medium or format, as long as you give appropriate credit to the original author(s) and the source, provide a link to the Creative Commons licence, and indicate if changes were made. The images or other third party material in this article are included in the article's Creative Commons licence, unless indicated otherwise in a credit line to the material. If material is not included in the article's Creative Commons licence and your intended use is not permitted by statutory regulation or exceeds the permitted use, you will need to obtain permission directly from the copyright holder. To view a copy of this licence, visit http:// creativecommons.org/licenses/by-nc/4.0/.

\section{REFERENCES}

1. Wang CCL, Hess CN, Hiatt WR, Goldfine AB. Atherosclerotic cardiovascular disease and heart failure in type 2 diabetes-mechanisms, management, and clinical considerations. Circulation. 2016;133(24):2459-502.

2. Osman AM, Carter SG, Carberry JC, Eckert DJ. Obstructive sleep apnea: current perspectives. Nat Sci Sleep. 2018;10:21-34.

3. Mazzotti DR, Keenan BT, Lim DC, Gottlieb DJ, Kim J, Pack AI. Symptom subtypes of obstructive sleep apnea predict incidence of cardiovascular outcomes. Am J Respir Crit Care Med. 2019;200(4): 493-506. 
4. Bundhun PK, Zi Jia W, Chen M-H. Impact of modifiable cardiovascular risk factors on mortality after percutaneous coronary intervention: a systematic review and meta-analysis of 100 studies. Medicine (Baltimore). 2015;94(50):e2313.

5. Maeder MT, Schoch OD, Rickli H. A clinical approach to obstructive sleep apnea as a risk factor for cardiovascular disease. Vasc Health Risk Manag. 2016;12:85-103.

6. Stang A. Critical evaluation of the Newcastle-Ottawa scale for the assessment of the quality of nonrandomized studies in meta-analyses. Eur J Epidemiol. 2010;25(9):603-5.

7. Liberati A, Altman DG, Tetzlaff J, et al. The PRISMA statement for reporting systematic reviews and meta-analyses of studies that evaluate healthcare interventions: explanation and elaboration. BMJ. 2009;21(339):b2700.

8. Fan J, Wang X, Ma X, Somers VK, Nie S, Wei Y. Association of obstructive sleep apnea with cardiovascular outcomes in patients with acute coronary syndrome. J Am Heart Assoc. 2019;8(2):e010826.

9. Lee CH, Khoo SM, Chan MY, et al. Severe obstructive sleep apnea and outcomes following myocardial infarction. J Clin Sleep Med. 2011;7:616-21.

10. Lee C-H, Sethi R, Li R, et al. Obstructive sleep apnea and cardiovascular events after percutaneous coronary intervention. Circulation. 2016;133(21): 2008-177.

11. Loo G, Tan AY, Koo C-Y. Prognostic implication of obstructive sleep apnea diagnosed by post-discharge sleep study in patients presenting with acute coronary syndrome. Sleep Med. 2014;15(6):631-6.

12. Meng S, Fang L, Wang C-Q, et al. Impact of obstructive sleep apnoea on clinical characteristics and outcomes in patients with acute coronary syndrome following percutaneous coronary intervention. J Int Med Res. 2009;37(5):1343-53.

13. Nakashima H, Kurobe M, Minami K, et al. Effects of moderate-to-severe obstructive sleep apnea on the clinical manifestations of plaque vulnerability and the progression of coronary atherosclerosis in patients with acute coronary syndrome. Eur Heart J Acute Cardiovasc Care. 2015;4(1):75-84.
14. Xiaofan Wu, Lv S, Xiaohong Yu, Yao L, Mokhlesi B, Wei Y. Treatment of OSA reduces the risk of repeat revascularization after percutaneous coronary intervention. Chest. 2015;147(3):708-18.

15. Yumino D, Tsurumi Y, Takagi A, et al. Impact of obstructive sleep apnea on clinical and angiographic outcomes following percutaneous coronary intervention in patients with acute coronary syndrome. Am J Cardiol. 2007;99:26-30.

16. Loke YK, William J, Brown L, Kwok CS, Niruban A, Myint PK. Association of obstructive sleep apnea with risk of serious cardiovascular events: a systematic review and meta-analysis. Circ Cardiovasc Qual Outcomes. 2012;5(5):720-8.

17. Rahangdale S, Yeh SY, Novack V, et al. The influence of intermittent hypoxemia on platelet activation in obese patients with obstructive sleep apnea. J Clin Sleep Med. 2011;7:172-8.

18. Karakaş MS, Altekin RE, Baktır AO, et al. Association between mean platelet volume and severity of disease in patients with obstructive sleep apnea syndrome without risk factors for cardiovascular disease. Turk Kardiyol Dern Ars. 2013;41:14-20. https://doi.org/10.5543/tkda.2013.42948.

19. Wang X, Fan J-Y, Zhang Y, Nie S-P, Wei Y-X. Association of obstructive sleep apnea with cardiovascular outcomes after percutaneous coronary intervention: a systematic review and meta-analysis. Medicine (Baltimore). 2018;97(17):e0621.

20. Hua Qu, Guo M, Zhang Y, Shi D-Z. Obstructive sleep apnea increases the risk of cardiac events after percutaneous coronary intervention: a meta-analysis of prospective cohort studies. Sleep Breath. 2018;22(1):33-40.

21. Wang X, Fan J, Yunhui Du, et al. Clinical significance of obstructive sleep apnea in patients with acute coronary syndrome in relation to diabetes status. BMJ Open Diabetes Res Care. 2019;7(1): e000737.

22. Correia LCL, Souza AC, et al. Obstructive sleep apnea affects hospital outcomes of patients with non-ST-elevation acute coronary syndromes. Sleep. 2012;35(9):1241-5. 